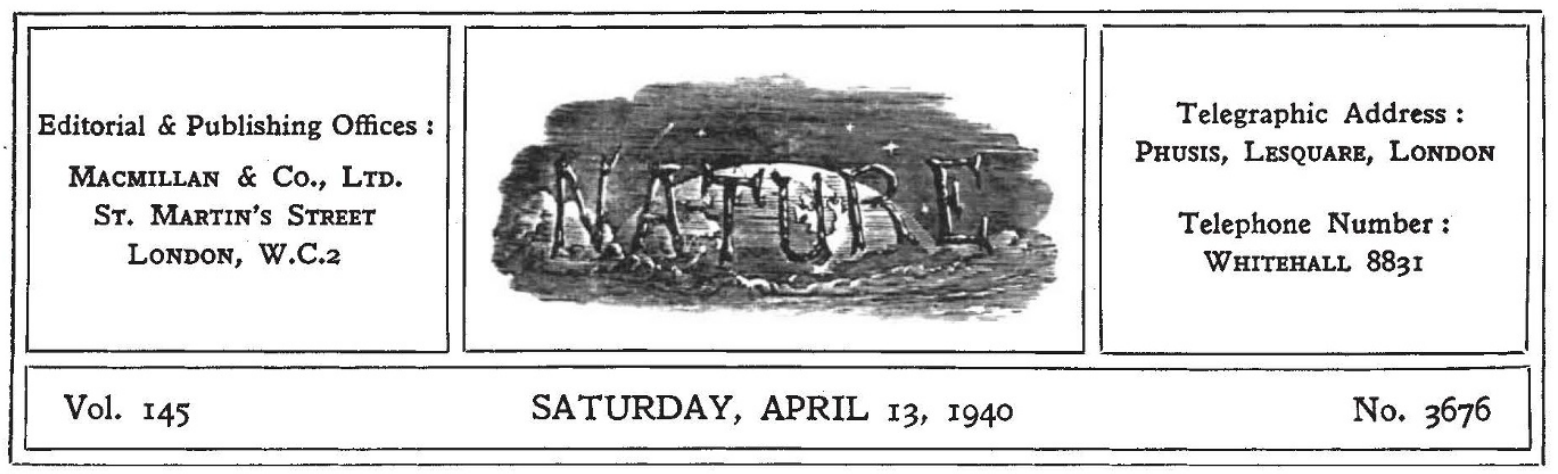

\title{
CO-OPERATION IN COLONIAL ADVANCEMENT
}

$\mathrm{U}$ NQUESTIONABLY the most striking fact to emerge from Lord Hailey's "African Survey" is the vastness of the field for scientific research and the application of its results to the needs of the native populations which are afforded by that continent. On a careful examination of the evidence which has been brought together of Lord Hailey's work of impartial observation, it is patent that if these peoples are to benefit to the full from the increased interest in their lot now manifested by the European Powers responsible for their future, a more carefully considered and scientifically informed approach to the problems of the administration of their affairs and of their future development is demanded. Nor is this an affair merely of the moment or the immediate future. No measures for the promotion of native advancement, however well-intentioned, will prove beneficial in the long run-as experience has shown time and again-which has not been framed in the light of the fullest knowledge of the essential character of native culture and its reactions to impact from outside.

As Lord Hailey has shown in detail, there is a considerable difference in outlook, in purpose and in method as between the administrative services of the various European powers concerned with African peoples. While it is doubtful whether it would be practicable, or even advisable in view of the wide differences in temperament, culture and attainment of the various African peoples, to attempt to secure absolute uniformity in administrative methods, yet unquestionably some agreement as to the general direction of policy in native development is more than desirable. In fact, sooner or later it may become an essential condition of European participation in the promotion of African development.
In these circumstances, it is a reassurance for the future that Allied co-operation is to be as effective in the colonial field as in other spheres of the joint interests of France and Great Britain. As a result of Mr. Malcolm MacDonald's recent conference in Paris, the more or less tentative approaches of the French and British colonial administrations in recent years are to be reinforced by the creation of an organization which will secure a permanent liaison between London and Paris. In the French and British Colonies themselves, which in many parts of the world, but more especially in Africa, lie adjacent to one another, there will be conferences from time to time between the governors of the British and French territories, while contact will be established between the administrative and specialist officers of the respective services.

How far this co-operation between French and British colonial authorities will lead ultimately towards any close community in fundamental principles of administrative policy it is of course at present impossible to say. On a superficial view, in outward form French colonial administrative methods, by the employment of native local chiefs and headmen, bear a certain resemblance to the methods of British 'indirect rule'; but there is at present a fundamental difference in attitude towards native authority as an instrument of administration. This would militate against anything in the nature of a condominium such as exists in the New Hebrides, which has been put forward by some as a desirable or possible outcome of the present approach to joint and common action in the Colonies between France and Britain.

British native administrative policy, fortified by experience in many parts of Africa, is wedded 
to the principle of 'indirect rule'; but it has not been thereby immune from criticism. On one hand, opinion among the more advanced and highly educated natives, especially in West Africa, is prone to regard its respect for native institutions and the desire to preserve their influence unimpaired as an attempt on the part of administrator and anthropologist to retard native development; on the other hand, the impartial judgment of qualified European observers fears an indiscriminate application of the principle in eircumstances in which its cardinal factor, the native in. stitution, is no longer operative, as for example in urbanized or industrialized populations, which have become cosmopolitan, in an African sense, rather than tribal. In the train of thought to which this gives rise, it is probably wise to give full weight to arguments which tend to emphasize the fact that 'indirect rule' in effect is 'local government' and stress its educative value.

At the same time, it should not be overlooked that in the light of the modern methods of investigation of social anthropology, the application of indirect rule has at times failed in scientific appreciation of the facts of native institutional practice upon which ex hypothesi it should be founded.

There is a larger and more far-reaching consideration to which attention may be directed. While indirect rule has as its immediate aim the preservation of tribal authority and the conservation of the forces which make for tribal integration, it does this as a means to an end-or so at least it is held by enlightened opinion-the ultimate advancement of the native peoples of Africa to take such a place among the peoples of the world as their capacities, circumstances and opportunities admit. However far they may have to go, some conception of direction, and the agencies by which this end is to be attained, should form a part of that planning on a world-wide basis which must in the long run be a consequence of the present struggle.

It is open to question, however, whether the colonial authorities, both at home and in the field, are not prone to overlook this consideration, and in danger of regarding indirect rule as to be pursued as an end in itself. Even the staunchest upholders of the principle appear to be somewhat vague as to ultimate aims. That the interests of the native population should be paramount, excellent as it may be as a principle of government, depends in its application too much upon the interpretation of 'interests' to afford any precise guidance.

In the recently issued White Paper on colonial development, while generous financial assistance is promised for both development and research, stress is laid on the primary purpose of assisting the colonies towards becoming self-supporting. Now Africa, as a whole and on the whole, is poor country, and in any event the burden of development for long must fall ypon white shoulders. In the course of that development, involving presumably a change-over from what is now a bare subsistence basis for the native population to something in the nature of an industrial or potentially commercialized form of production, concern for native 'interests' may be in danger of suffering a sensible diminution.

The issues involved in the relations of a white and a native African population have been set out, though in a widely different context from that in which indirect rule has been applied, with admirable lucidity and an absence of bias by Prof. R. F. A. Hoernlé in his Phelps-Stokes Lectures for 1939*. He discusses there the native problem as it now presents itself in the Union of South Africa. As in other of the older colonies of Great Britain in Africa, the relations of white and black in South Africa up to a point have reflected the growth of a sense of responsibility in the mother country, whether due to the humanitarianism which abolished slavery or the consciousness of the 'white man's burden,' by which, in the eyes of many, imperialistic expansion found its justification. It has its modern counterpart in the 'trusteeship' which is now the avowed principle of the mandatory and colonial administration. In South Africa, however, the 'liberal spirit' which once fostered native advancement has given way, under stress of racial feeling, which is closely bound up with questions of economic competition, to a reaction which approaches native policy primarily and to all intents and purposes solely from the point of view of the maintenance of the dominance of the white and superior race in the Union. When it is remembered that here the black population outnumbers the white in the ratio of between three and four to one, the difficulties which confront those who advocate a more liberal approach to the problem become easily understood.

* South African Native Policy and the Liberal Spirit: being the Phelps-Stokes Lectures delivered before the University of Cape Town, May 1939. By R. F. Alfred Hoernlé. Pp. xiv +190. (Lovedale, May 1939. By R. F. Alfred Hoernlé.
C. P. : The Lovedale Press, 1939.) 58. 
It is a far cry from the complexity of social and racial conditions in South Africa to the relatively simpler societies to which indirect rule has been applied. Yet the germs of South Africa's problem are there; and they will grow unless measures be taken in time. It has been said that we are waging a war in which the aim of the Allies is to establish Christian civilization as against the paganism of nationalism and the worship of the State. But as Sir Francis Younghusband has pointed out, neither Islam nor Hinduism, nor Confucianism nor other creeds can be excluded from our aims, insomuch as we welcome their assistance. Our battle is for the principles which lie at the root of Christianity, it is true, but are no less the articles of faith of all men of good will irrespective of creed-the dignity and integrity of the individual man free to develop mind and body to the limits of his capacity within free institutions. For better or for worse, white civilization has impinged upon the black. It is incumbent upon us, if we are to be really true to the principles for which we stand in the present struggle, to see to it that our rule over the less advanced peoples is a tutelage which does not overlook their claims to co-operate in a world order in the coming era of, we hope, a more rational, as well as a more humanitarian, world.

\section{ANGLO-FRENCH CO-OPERATION IN SCHOOLS}

$\mathrm{O}^{\mathrm{N}}$ N September 3, Lord De La Warr, who was then president of the Board of Education, visited Paris to discuss with the French Minister of Education, M. Sarraut, the contribution which the schools of the two countries can make towards Anglo-French solidarity.

The event followed a discussion in London at the end of January last on intellectual co-operation between visiting French Ministers and their opposite numbers. Committees were afterwards set up by the Education Ministries of both countries, the aim of which is to develop existing means and to devise fresh ones for increasing among the school children of each country knowledge and appreciation of the life and culture of the other country. During the visit, which was marked by a broadcast in French by M. Sarraut and Lord De La Warr, members of the two committees met to discuss each other's work. After the visit to London to which we have already referred, a special commission of experts was set up in France to recommend ways of ensuring that French children obtain a thorough knowledge of Britain and the British, the affinities and differences of the two peoples, and their common aims in civilization. Any report which the commission has now prepared would doubtless be discussed during the Paris visit.

This move towards closer intellectual co-operation would have been desirable even had there been no war. In the present circumstances, it is inevitable and essential as a part of plans for Allied co-operation which grow more and more comprehensive. The Anglo-French declaration of war and peace policy carries with it the necessity of closer contacts between the youth and intellectual life of the two countries. Upon those who are young now will rest the responsibility of clinching victory and securing the maintenance of peace in the future. That responsibility must obviously entail closer understanding in the realm of ideas. It is in the schools, as Lord De La Warr pointed out in his broadcast, that the two peoples, so different in many ways, can learn of one another. It is in the schools that they may learn what they have both given, and are giving, to civilization and culture, what are the things for which, and against which, the present war is being waged. There was grim warning in Lord De La Warr's statement that, from the point of view of the future, the most terrible crime of the Nazi régime is the deliberate perversion of the minds and souls of their young people.

In France, where educational machinery is more centralized than in Britain, rapid innovations are possible. In English schools, nevertheless, special means have already been devised towards the ends in view. More than half a million are learning French, and the number can be increased by new effort. New programmes have been drawn up for school broadcasts and new plans for a wide circulation of films and for special lecturers to tour the schools. There are possibilities, too, of new books on French life, and of arranging exchange visits of teachers and children. These activities should make a substantial contribution to the preservation and development of the ideals for which Britain and France stand. 